Please do not remove this page

RMIT

UNIVERSITY

\title{
A review of operations research methods applicable to wildfire management
}

Minas, James; Hearne, John; Handmer, John

https://researchrepository.rmit.edu.au/esploro/outputs/9921858022801341/filesAndLinks?institution=61RMIT_INST\&index=null

Minas, J., Hearne, J., \& Handmer, J. (2012). A review of operations research methods applicable to wildfire management. International Journal of Wildland Fire, 21(3), 189-196. https://doi.org/10.1071/WF10129

Document Version: Accepted Manuscript

Published Version: https://doi.org/10.1071/WF10129

Repository homepage: https://researchrepository.rmit.edu.au

(C) 2012 IAWF

Downloaded On 2023/04/26 11:54:28 +1000

Please do not remove this page 
Thank you for downloading this document from the RMIT Research Repository.

The RMIT Research Repository is an open access database showcasing the research outputs of RMIT University researchers.

RMIT Research Repository: http://researchbank.rmit.edu.au/

\section{Citation:}

Minas, J, Hearne, J and Handmer, J 2012, 'A review of operations research methods applicable to wildfire management', International Journal of Wildland Fire, vol. 21, no. 3, pp. 189-196.

See this record in the RMIT Research Repository at:

http://researchbank.rmit.edu.au/view/rmit:16359

Version: Accepted Manuscript

Copyright Statement: (c) 2012 IAWF

Link to Published Version:

http://dx.doi.org/10.1071/WF10129

\section{PLEASE DO NOT REMOVE THIS PAGE}




\section{A review of operations research (OR) methods applicable to wildfire management}

3 Suggested running head: A review of OR methods for wildfire management

5 James P. Minas A B C, John W. Hearne ${ }^{\text {A }}$, John W. Handmer A B

$6 \quad{ }^{\text {A }}$ School of Mathematical and Geospatial Sciences, RMIT University, Melbourne, VIC 3001, Australia.

$7 \quad$ B Bushfire Cooperative Research Centre, Melbourne, VIC 3002, Australia.

$8 \quad{ }^{\mathrm{C}}$ Corresponding author. Email: james.minas@rmit.edu.au

\section{Abstract}

Across the globe wildfire-related destruction appears to be worsening despite increased fire suppression expenditure.

13 At the same time, wildfire management is becoming increasingly complicated due to factors such as an expanding

14 wildland-urban interface, inter-agency resource sharing and the recognition of the beneficial effects of fire on

15 ecosystems. OR is the use of analytical techniques such as mathematical modelling to analyse interactions between

16 people, resources and the environment to aid decision-making in complex systems. Fire managers operate in a highly

17 challenging decision environment characterised by complexity, multiple conflicting objectives and uncertainty. We

18 assert that some of these difficulties can be resolved with the use of OR methods. We present a range of OR methods

19 and discuss their applicability to wildfire management with illustrative examples drawn from the wildfire and disaster

20 OR literature.

Additional keywords: bushfire, forest fire, wildland fire, operational research, decision-making, management science

Summary for Table of Contents

26 Wildfire managers operate in a highly challenging decision environment characterised by complexity, multiple conflicting objectives and uncertainty. Operations research (OR) is a discipline that uses analytical techniques to aid 
28 decision making in complex systems. This paper discusses a range of OR methods available to assist wildfire 29 managers with illustrative examples drawn from the wildfire and disaster OR literature. 
Introduction

The February 2009 bushfires in Victoria, Australia provided a stark reminder of the destructive potential of wildfire.

33 The fires resulted in 173 fatalities and damage to property, infrastructure and the natural environment with an

34 estimated total cost of over A \$4 billion (Teague et al. 2010). Globally, wildfire-related destruction is a problem that appears to be worsening. In the Mediterranean basin a sharp increase in wildfire events has been observed over the past several decades despite increased investment in prevention and suppression (Carmel et al. 2009; Pappis and Rachaniotis 2010). Increased wildfire activity has also been observed in the United States (Westerling et al. 2006) and Canada (Podur et al. 2002). This upward trend appears set to continue due to rising temperatures and changed weather conditions associated with climate change (Wotton et al. 2003; Westerling et al. 2006). As suppression expenditures continue to rise, governments seek wildfire management approaches that are economically efficient and that take into account both market and non-market benefits (Venn and Calkin 2011).

43 Wildfire managers operate in a difficult decision environment. They are faced with limited time, constrained 44 resources, extreme uncertainty and multiple objectives that may conflict (Martell et al. 1998). In recent years, wildfire management has become increasingly complex with the advent of inter-agency resource sharing arrangements and the recognition of the beneficial effects of fire on ecosystems (Martell 2011). Operations Research (OR) is a discipline that is uniquely placed to assist managers operating in this challenging environment. OR is the use of analytical techniques such as mathematical modelling to analyse complex interactions between people, resources and the environment to aid decision-making and the design and operation of systems (Altay and Green 2006). Wildfire managers have access to a proliferation of data from a variety of sources including geospatial databases and fire behaviour and climatology models. OR methods can provide a framework to help wildfire managers make sense of this information and use it to guide decision-making.

54 There is a large body of disaster management OR work relating to non-routine emergency events such as: earthquakes, floods and hurricanes (Altay and Green 2006). There is also a substantive literature on the application of 
57 work from 1961 to 1981 with elements of this review updated in 1998 (Martell et al. 1998), as such this paper will 58 focus on post-1998 wildfire OR work. The remainder of the paper is structured as follows. A range of OR methods 59 will be discussed in terms of their ability to address some of the defining challenges of wildfire management, namely:

60 complexity, multiple conflicting objectives and uncertainty. Illustrative examples and case studies drawn from the

61 wildfire and disaster OR literature will be presented for each of the OR methods discussed. 


\section{Methods for handling complexity}

\section{$64 \quad$ Mathematical programming}

Wildfire managers are often faced with complex problems consisting of a large number of inter-related decisions

67 together with resourcing and other operational constraints. Mathematical programming (MP) is a field of OR that can

68 assist with such problems. MP methods are concerned with the optimization, that is maximization or minimization, of

69 some explicit and quantifiable objective (Williams 1990). In an MP model this objective is defined as a mathematical

70 function of the decision variables in the form of an 'objective function' and is optimized subject to a series of related

71 constraints (Hillier and Lieberman 2005). Several categories of MP: linear programming (LP), integer programming

72 (IP), nonlinear programming (NLP) and dynamic programming (DP ) are described in further detail below together

73 with examples from the wildfire and disaster OR literature.

75 Linear programming (LP) can be used when a problem's objective function and constraints can be formulated as a

76 linear combination of the decision variables (Ragsdale 2008). Hof et al. (2000) developed a timing-oriented LP model

77 for the spatial allocation of suppression effort for an existing fire. Their model's objective was to delay the ignition of

78 "protection areas" such as population centres. In an extension of this work Hof and Omi (2003) described the

79 application of a similar timing-oriented LP model to a fuel management scheduling problem. In their model, spatial

80 application of fuel-reduction treatments were determined so as to mitigate the effects of a particular "target fire" with

81 a known origin and spread behaviour. When a LP model is solved a "shadow price" is generated for each constraint as

82 a standard model output. Shadow prices can be interpreted as the marginal effect that tightening or relaxing a

83 constraint has on the objective value obtained (Williams 1990). Armstrong and Cumming (2003) used shadow prices

84 obtained from a timber-harvesting LP model to estimate the potential cost of land based changes due to wildfire.

85 Spatially explicit values-at-risk information like this can be useful for fuel treatment and suppression preparedness

86 planning. 
88 Integer programming (IP) models feature inputs or outputs that are required to take on discrete whole number values.

89 IP can be useful for modelling problems that feature: indivisible resources, "yes or no" decisions or logical

90 connections such as "if" and "then" (Wolsey 1998). IP methods have been applied to a range of wildfire management

91 problems. The maximal covering location model (MCLM) is a classic IP model that has been used extensively in

92 emergency service deployment (Church and ReVelle 1974). Dimopoulou and Giannikos (2001; 2004) described the

93 use of an MCLM model for suppression resource deployment as part of a decision support system that also included a

94 simulation module and a GIS interface. Kirsch and Rideout (2005) presented an IP model for initial attack

95 preparedness planning. Their model deployed initial attack resources across a user-defined set of fires with the

96 objective being to maximise the weighted area protected (WAP) for a given level of budget funding, with weights

97 assigned based on protection priorities. Donovan (2006) presented a model for determining the optimal mix of agency

98 and contract fire crews to minimise costs and satisfy demand across a fire season. A multi-period transportation

99 formulation was used with the fire season modelled as a series of discrete time periods with differing levels of

100 demand. This approach resulted in reduced computational complexity for this type of problem as compared to a

101 standard IP formulation. Donovan and Rideout (2003) described an IP model to determine the optimal mix of fire-

102 fighting resources to dispatch to a given fire to achieve containment with minimal resultant costs and damages. Wei et

103 al. (2008) formulated an IP model for optimal allocation of fuel treatment across a landscape based on spatially

104 explicit ignition risk, fire spread probability, fire intensity levels and values-at-risk. Higgins et al. (2011) used an IP

105 approach to develop a seasonal resource allocation model for planning fuel reduction burning on public lands in

106 Victoria, Australia.

108 Nonlinear programming (NLP) methods are used when a problem features a nonlinear objective function or nonlinear 109 constraints. The probability of containing a wildfire and the suppression time required to do so are nonlinear functions 110 of fire size at the start of initial attack. This means small delays in dispatch of initial attack resources can result in 111 dramatic fire loss increases (MacLellan and Martell 1996). Rachaniotis and Pappis sought to incorporate this element 112 of fire behaviour in an NLP model via the use of the "deteriorating jobs" concept. Their model tackled the problem of 113 scheduling a single fire-fighting resource when there are several existing fires to be controlled (Rachaniotis and 114 Pappis 2006; Pappis and Rachaniotis 2010; Rachaniotis and Pappis 2011). The model was subsequently extended to 115 allow scheduling of multiple fire-fighting resources (Pappis and Rachaniotis 2009). Minciardi et al. (2009) formulated 
116 two related NLP models, one for deployment of wildfire suppression resources in the pre-operational phase and the

117 other for dispatch of resources to fires in the operational phase.

119 Dynamic programming (DP) is an optimisation method that is particularly useful when sequences of interrelated

120 decisions need to be made. In deterministic DP the state of the system at the next stage is completely determined by

121 the current system state and the policy decision made (Hillier and Lieberman 2005). Wiitala (1999) used a DP model

122 to determine the most efficient mix of available initial attack resources to dispatch to a fire. 
125 Traditional 'OR' methods such as mathematical programming are suited to well-structured problems that can be 126 clearly formulated in terms of performance measures, constraints and relations between action and consequence. 127 However, many wildfire and disaster management problems lack structure and are typified by multiple perspectives, 128 disagreement amongst experts and the presence of intangibles and uncertainties. Problem structuring methods (PSM) 129 are a suite of techniques that can assist in resolving some of these difficulties. Compared to traditional 'hard' OR 130 methods PSM typically employ rudimentary mathematical or statistical techniques (Mingers and Rosenhead 2004).

131 Two PSM methods, decision conferencing and expert judgement elicitation, are discussed in further detail below.

133 Decision conferencing can be an effective method for assisting with longer-term collaborative decision making. A 134 decision conference is typically a two-day event that brings together decision makers from various organisations to 135 discuss issues and work out a way forward. A facilitator is present to keep the discussion focused. An analyst is also 136 present to build a series of analytical decision models with a view to developing a shared understanding of the 137 problem (French 1996). A series of decision conferences were held in the USSR following the 1986 Chernobyl 138 nuclear accident. The aim was to identify the major factors influencing decision-making on relocation and other long 139 term protective measures. The decision conferences helped develop a common understanding amongst participants 140 including government ministers, policy-makers and scientists and successfully identified a number of key medical, 141 socio-economic and political factors influencing protective measures undertaken (French et al. 1992). Decision 142 conferencing could be similarly used following major wildfires to facilitate dialogue between stakeholders and aid 143 recovery-phase planning.

145 Expert judgement elicitation (EJE) is the use of structured methods to elicit expert opinions in a planned, formal manner that attempts to minimize bias. EJE typically involves interviewing or surveying "subject experts" and then 147 analysing their answers together with information about their background and experience. EJE methods can provide 148 an understanding of the degree of and reasons for consensus or disagreement amongst experts and can be useful in 149 facilitating learning and dialogue (Gregory et al. 2006). Furthermore, EJE studies are often a cost-effective and 150 practical means of obtaining valuable information. In the wildfire context, EJE methods have been used to estimate 
151 fire containment probabilities and fire-line construction rates. In these instances, alternate methods such as

152 observation of actual or experimental fires are often deemed to be too expensive, time-consuming and dangerous

153 (Hirsch et al. 1998). In one of the earliest applications of EJE methods to wildfire management subjective probability

154 assessments of daily forest fire occurrence were derived using information elicited from experienced fire managers in

155 Ontario (Cunningham and Martell 1976). Hirsch et al. (1998) used an EJE approach to model the relationship between

156 fire size, fire intensity and probability-of-containment by a 5-7 person initial attack crew. In their study they

157 interviewed crew leaders from four Canadian forest fire agencies and elicited probability-of-containment estimates for

158 various fire scenarios (Hirsch et al. 1998). Gilless and Fried (2000) surveyed California fire-fighters and used their

159 responses to estimate probability distributions for fire-line construction rates for different fire-fighting resources under

160 a range of conditions. These fire-line construction rate distributions were subsequently incorporated into the CFES2

161 simulation model used for initial attack planning in California. Similarly, Hirsch et al. (2004) interviewed crew

162 leaders in Ontario and developed probability distributions for production rates of three and four person initial attack

163 crews for a range of fuel types and fire intensities. Rideout et al. (2008) used EJE methods in their Marginal Attribute

164 Rate of Substitution (MARS) approach to assessing values-at-risk for initial attack planning. 
167 In complex systems, components can interact with one another via a web of feedback loops meaning a small change 168 to input parameters can produce a drastic change to the whole system (Anderson 1999). These feedback effects can be 169 modelled using system dynamics (SD). Unlike many traditional 'hard' OR approaches that are static and linear in 170 character, SD can accept the nonlinearity and feedback loop structures of real world social and physical systems.

171 Whilst SD uses a 'soft' PSM-like approach for information elicitation and problem structuring, it includes two 172 additional 'hard' steps: model definition using rate and level equations and the running of model simulations. An SD 173 model initially serves to demonstrate how the problem under consideration is being generated in the real world, it is 174 subsequently used to test alternative policies and structures (Forrester 1994). Hoard et al. (2005) discussed the 175 application of SD methods to disaster preparedness planning in rural areas with a focus on hospital surge capacity for 176 a variety of disaster types. A similar SD approach could be used in wildfire preparedness planning to explore surge 177 capacity considerations in suppression resource deployment and rostering of fire-fighting personnel. 


\section{Hyper-projects}

180 Wildfire incident controllers are dealing with a problem that is emergent in nature. They are faced with a 'moving

181 target' or a dynamic set of changing circumstances. The incident trajectory is influenced by actions taken such as fire suppression and external forces such as weather (Faraj and Xiao 2006). Simpson (2006) defined a class of project, the

183 'hyper-project', that captures these emergent characteristics. Hyper-projects are characterised by the presence of a

184 dynamic, external 'pacing function' and a set of defined tasks and resource requirements that interact with this pacing

185 function. Time pressure is an inherent feature of hyper-projects, with tasks measured in minutes or hours. Simpson 186 (2006) used the hyper-project construct to model response to a residential structure fire, a similar approach could be 187 used to model real-time wildfire suppression decision-making. In such a model various suppression resources would

188 be dispatched and tactical fire-fighting decisions made relative to an external pacing function, which in this case 189 would be the growth and lifecycle of the uncontained wildfire. The hyper-project approach can capture threshold 190 effects, a key feature of complex biophysical systems. Thresholds are breakpoints that occur in systems with multiple 191 stable states where crossing a threshold results in a shift from one state to another (Berkes 2007). An example being 192 when a wildfire crosses the $4000 \mathrm{~kW} / \mathrm{m}$ threshold it can be said to have changed state from a controllable fire to a spot 193 generating fire (Gill 2005) thus requiring a different suppression response. The hyper-project provides a framework 194 for responding to state changes via the execution of a flexible set of tasks that vary in a pre-defined manner relative to 195 the pacing function. 
Methods for handling multiple conflicting objectives

\section{Multi-objective optimization}

Wildfire management involves various agencies and groups with different priorities and objectives including:

reduction of impacts on public safety, private property and ecosystem processes as well as cost minimisation (Martell 2007). Instances will often arise where multiple objectives conflict with one another, for example frequent planned burning can provide additional protection to built assets but may have a negative impact on biodiversity in some ecosystems (Driscoll et al. 2010). Where multiple objectives can be expressed in terms of market values they can be aggregated into a single cost minimization objective. However wildfire managers are required to consider potential impacts on non-market values such as: ecosystem health, conservation of flora and fauna, air quality, water quality, recreational opportunities and cultural heritage (Venn and Calkin 2011). In many cases ascribing a monetary value to these items would be an expensive, time-consuming and uncertain exercise. This lack of a common currency makes it difficult to evaluate and compare the outcomes of decisions or strategies. Multi-objective optimization (MO) is a technique that is suited to these types of problems. MO models are formulated with more than one objective function to find a set of Pareto optimal solutions. A solution is Pareto optimal if none of the objectives can be improved without making another objective worse. Decision-makers can assess alternatives from this set of Pareto optimal 214 exploration of trade-offs provides a level of transparency in the decision process (Gregory et al. 2006). Lehmkuhl et al. (2007) described FUELSOLVE a prototype decision support system that incorporates MO modelling into fuel management decision-making to consider both ecological and cost objectives. Kennedy et al. (2008) demonstrated the use of the FUELSOLVE MO model with a fuel treatment case study with trade-offs assessed between protection of endangered species habitat, preservation of old growth forest reserves and minimization of area treated.

Goal Programming (GP) is a branch of multi-objective optimization in which each of the multiple objectives takes the form of a goal. Goals are formulated as 'soft constraints' each with a target value it is desirable to satisfy. A penalty 
223 function parameters allows the exploration of trade-offs between objectives (Ragsdale 2008). Calkin et al. (2005) used

224 a GP approach to analyse trade-offs between fire threat reduction and habitat preservation in silvicultural treatment

225 scheduling. A goal programming module is currently under development as part of the United States Fire Program

226 Analysis (FPA) project (Kumar et al. 2010). The FPA project has been undertaken by the US Forest Service and other

227 federal land management agencies in an attempt to develop a wildfire management planning and budgeting decision-

228 support tool that will incorporate a full range of both market and non-market objectives (Venn and Calkin 2011). 
Methods for handling uncertainty

\section{Simulation}

233 Wildfire managers are required to make difficult decisions in conditions of uncertainty. Simulation is arguably the 234 most robust and easily applied method for consideration of uncertainty in decision support systems (Mowrer 2000).

235 Simulation is an approach used to model real-life stochastic systems that evolve probabilistically over time. The real236 life system's performance is imitated by using probability distributions to generate various events that occur in the 237 system (Hillier and Lieberman 2005). Prior to implementation, simulation models require validation to ensure they 238 realistically represent the system being analysed and that the results they provide are reliable (Winston 1994).

239 Simulation models feature in a number of decision support systems used by wildfire agencies for strategic planning 240 purposes. The California Fire Economics Simulator version 2 (CFES2) is a stochastic simulation model that simulates

241 fire occurrence and suppression on a daily basis. Simulation of many years of "data" makes it possible to undertake

242 "what if" analysis for changes to organisational components such as: resource stationing, dispatch rules and staff 243 schedules (Fried et al. 2006). The Level of Protection Analysis System (LEOPARDS) is underpinned by a simulation 244 model that is spatially conscious and incorporates temporal queuing conflicts. LEOPARDS can model daily fire 245 suppression activities and is used in Ontario to assess initial attack performance under a range of policy and budget 246 conditions (McAlpine and Hirsch 1999). LEOPARDS has evolved from an initial attack simulation model that was 247 developed in the early 1980s by Martell et al. (1984). The USDA Forest Service's National Fire Management 248 Analysis System (NFMAS) Interagency Initial Attack Assessment (IIAA) is a simulation model that has been used in 249 the past to test alternative initial attack organisations and strategies at various budget levels with a view to 250 determining the Most Efficient Level (MEL) of funding (Lundgren 1999). Manipulation of simulation models can 251 provide valuable insights into a problem, however the primary shortcoming of this approach is that it is only possible 252 to find "the best" management alternative from those investigated. For large problems with many management 253 alternatives it is unlikely that a near-optimal solution can be found in this manner. For this reason, mathematical 254 programming (MP) methods that systemically explore the solution-space can add significant value to complex 255 wildfire management problems (Hof and Haight 2007). 
258 Stochastic programming (SP) is a method that combines mathematical programming methods with probability

259 techniques to provide a constructive approach to tackling optimization problems that feature uncertain data. SP can be 260 used when there are uncertain model parameters with probability distributions that are known or can be estimated 261 (Kall and Wallace 1994). These parameter distributions can be either continuous or described by discrete scenarios and in some cases are generated using simulation techniques. The most common SP objective is optimization of the mean outcome or expected value of the system. An alternate formulation incorporating decision maker risk preferences is the optimization of a weighted sum of expected value and variance (Snyder 2006). SP models generate solutions that are less sensitive to data uncertainty than deterministic MP models, however large SP models can prove difficult to solve.

One of the earliest uses of SP methods in forest fire management was Boychuk and Martell's (1996) multi-stage model for forest-level timber management that considered uncertain losses that could result from fires. A common SP

270 formulation is the two-stage model with recourse. In such models, a first-stage decision is made after which a random event occurs, a recourse decision can then be made in the second-stage that compensates for any undesirable effects. Hu and Ntaimo (2009) modelled the wildfire initial attack dispatch problem as a two-stage SP model with recourse. In their model the first stage decisions related to dispatch of suppression resources to reported wildfires, with recourse decisions made on fire-fighting tactics in the second stage. Stochastic parameters in the model included: fire growth scenarios, fire-line production rates, arrival times to fires and suppression resource operating costs. Ntaimo (2010)

276 described an alternate application of a two-stage SP approach with deployment of suppression resources to bases in 277 the first-stage and dispatch of resources to wildfires in the second stage. Two-stage SP models have been applied to a 278 range of disaster management problems including: transportation of first-aid commodities on a disaster effected road network (Barbarosoglu and Arda 2004), pre-positioning of emergency supplies in a hurricane-threatened region 
283 Probabilistic SP approaches, such as chance-constrained programming, require the probability of a constraint holding

284 to be above a specified threshold (Snyder 2006). Bevers (2007) demonstrated the use of chance-constrained

285 programming for a fire organisation budgeting problem. In his model formulation the probability of total fire costs

286 exceeding the budget was required to be less than a specified risk level.

288 Stochastic dynamic programming (SDP) is a method used for problems with sequential decisions that are subject to

289 uncertainty. SDP differs from deterministic DP in that state-to-state system transitions are governed by probability

290 distributions (Hillier and Lieberman 2005). Konoshima et al. (2008; 2010) demonstrated the use of an SDP approach

291 for determining optimal spatial patterns of fuel treatment and timber harvesting in a theoretical landscape subject to

292 fire risk. Spring and Kennedy (2005) developed an SDP model with decisions made at the beginning of each stage as

293 to which stands of trees are harvested and what level of fire protection is applied. 
Robust optimization

296 Like stochastic programming (SP), robust optimization (RO) provides a constructive approach to solving optimization 297 problems that feature uncertain data (Vladimirou and Zenios 1997). However RO differs from SP in that probability 298 distributions of uncertain parameters are not required. All that needs to be known about the uncertain parameters is 299 that they belong to some "uncertainty set" which may be described as either a continuous interval or as set of discrete 300 scenarios (Ben-Tal and Nemirovski 2002). RO models are a great deal less sensitive to data perturbations than 301 deterministic MP methods but substantially more difficult to solve. RO models can be formulated in a number of 302 ways. The Minimax formulation seeks to minimise the maximum cost or damage across all possible scenarios. This is 303 a highly conservative approach that provides costly solutions that cater for worst-case outcomes (Snyder 2006).

304 Unless a model has significant built-in redundancies a solution is unlikely to remain both feasible and optimal across 305 all scenarios (Vladimirou and Zenios 1997). Model and solution robustness approaches seek to balance optimality and

306 feasibility based on the decision maker's degree of risk aversion. Restricted scenario approaches minimise the 307 maximum cost or damage across a restricted 'reliability set' of scenarios. This reliability set is specified by the 308 decision maker based on risk preferences (Snyder 2006). Haight and Fried (2007) presented a scenario-optimization 309 IP model for suppression resource deployment based on the classical maximal covering model (MCLM). Their 310 formulation included a binary "standard response" variable that served as a proxy for fire-line construction. The 311 model's objective was to minimize the number of fires not receiving a "standard response" across a defined set of 312 scenarios. Mercer et al.(2008) modified Haight and Fried's standard-response model to incorporate the effects of fuel 313 treatment. Other problems with relevance to wildfire and disaster management that RO methods have been applied to 314 include evacuation transportation planning (Yao et al. 2009) and facility location under uncertainty (Snyder 2006). 


\section{$315 \quad$ Fuzzy models}

317 Stochastic programming and robust optimization methods are appropriate for problems where uncertainty is mostly

318 due to randomness, however uncertainty is sometimes due to other factors such as imprecision and ambiguity

319 (Verderame et al. 2010). Fuzzy set theory is an approach that can tackle problems that feature fuzzy predicates such as 320 'small' or 'safe', fuzzy quantifiers such as 'most' or 'often', and fuzzy probabilities such as 'likely' or 'unlikely'

321 (Smithson 1991). In classical set theory membership of a set is assessed in binary terms, that is an element either 322 belongs to a set or it doesn't. In fuzzy set theory 'degrees of membership' ranging from 0 to 1 are permitted based on 323 a fuzzy membership function (Dubois and Prade 1988). Models based on fuzzy set theory have been used to classify 324 areas into risk-zones for both fire prevention planning (Iliadis et al. 2002), (Iliadis et al. 2002b), (Iliadis 2005), (Iliadis 325 and Spartalis 2005), (Kaloudis et al. 2005), (Kaloudis et al. 2008), (Tsataltzinos et al. 2009), (Iliadis et al. 2010) and 326 disaster relief purposes (Sheu 2007), (Tan et al. 2009), (Sheu 2010). 


\section{Conclusion}

329 In this paper we have presented a range of OR methods and discussed their ability to address some of the major 330 challenges of wildfire management including: complexity, multiple conflicting objectives and uncertainty. Many of 331 these OR methods are complimentary and can be used in conjunction with one another. Problem structuring methods 332 (PSM) can be used to elicit objectives and opinions and to help develop a common understanding. Simulation and 333 system dynamics (SD) methods can be used to model the dynamics of complex systems to gain insights into the 334 problem structure and possible management prescriptions through the use of "what-if" analysis. Whilst optimization 335 methods such as mathematical programming (MP) can be used to explore the decision space and seek good solutions 336 from the many alternatives.

As more frequent and destructive wildfire events threaten lives and homes in an expanding wildland-urban interface,

339 now more than ever we need to apply best practice analytical methods to assist wildfire managers in assessing

340 alternatives and making decisions. However, there appears to be a large and growing gap between the decision

341 support needs of fire managers and the decision support tools currently available (Martell 2011).We have

342 demonstrated with the use of examples from the literature the role OR techniques can play in bridging this gap. The

343 Victorian Bushfires Royal Commission investigated the catastrophic 2009 bushfires and made a series of

344 recommendations aimed at reducing the risk and impacts of fire and minimising fire-related loss of life (Teague et al.

345 2010). Of the 67 recommendations made, fifteen could be addressed with the use OR methods, including:

346 consideration of multiple objectives in fuel treatment planning and pre-emptive risk-based deployment of aerial 347 resources.

349 The many wildfire OR examples discussed in this paper range from those that are largely theoretical in nature to those 350 that have been successfully implemented, such as the LEOPARDS model (McAlpine and Hirsch 1999). As OR 351 formulation methods and algorithms continue to improve and greater computing power become available, it will be 352 possible to tackle increasingly complex wildfire problems using OR methods. However in closing, it is apt to recall 353 Martell's (1982) reminder that OR specialists can develop decision-making aids that will enhance but not replace the 
354 experience and intuition of wildfire managers, and that the successful application of OR methods will require the OR 355 analyst to work closely with wildfire agency personnel.

357 Acknowledgements

359 This work was supported by funding from the Bushfire Cooperative Research Centre in the form of scholarship 360 funding to James Minas. This manuscript has benefitted from the comments and suggestions of anonymous reviewers. 
References

362

363

364

365

366

367

368

369

370

371

372

373

374

375

376

377

378

379

380

381

382

383

384

385

386

387

388

389

390

391

392

393

394

395

396

397

398

399

400

401

402

403

404

405

406

407

408

409

410

411

412

413
Altay N, Green WG (2006) OR/MS research in disaster operations management. European Journal of Operational Research 175(1), 475-493.

Anderson P (1999) Complexity theory and organization science. Organization Science 10(3), 216-232.

Armstrong G, Cumming S (2003) Estimating the cost of land base changes due to wildfire using shadow prices. Forest Science 49(5), 719-730.

Barbarosoglu G, Arda Y (2004) A two-stage stochastic programming framework for transportation planning in disaster response. Journal of the Operational Research Society 55(1), 43-53.

Ben-Tal A, Nemirovski A (2002) Robust optimization-methodology and applications. Mathematical Programming 92(3), 453-480.

Berkes F (2007) Understanding uncertainty and reducing vulnerability: lessons from resilience thinking. Natural Hazards 41(2), 283-295.

Bevers M (2007) A chance constraint estimation approach to optimizing resource management under uncertainty. Canadian Journal of Forest Research 37(11), 2270-2280.

Boychuk D, Martell DL (1996) A multistage stochastic programming model for sustainable forest-level timber supply under risk of fire. Forest Science 42(1), 10-26.

Calkin D, Hummel S, Agee J (2005) Modeling trade-offs between fire threat reduction and late-seral forest structure. Canadian Journal of Forest Research 35(11), 2562-2574.

Carmel Y, Paz S, Jahashan F, Shoshany M (2009) Assessing fire risk using Monte Carlo simulations of fire spread. Forest Ecology and Management 257, 370-377.

Chang MS, Tseng YL, Chen JW (2007) A scenario planning approach for the flood emergency logistics preparation problem under uncertainty. Transportation Research Part E-Logistics and Transportation Review 43, 737-754.

Church R, ReVelle C (1974) The maximal covering location problem. Papers in regional science 32(1), 101-118.

Cunningham A, Martell DL (1976) The use of subjective probability assessments to predict forest fire occurrence. Canadian Journal of Forest Research 6(3), 348-356.

Dimopoulou M, Giannikos I (2001) Spatial optimization of resources deployment for forest-fire management. International Transactions in Operational Research 8(5), 523-534.

Dimopoulou M, Giannikos I (2004) Towards an integrated framework for forest fire control. European Journal of Operational Research 152(2), 476-486.

Donovan G (2006) Determining the optimal mix of federal and contract fire crews: A case study from the Pacific Northwest. Ecological Modelling 194(4), 372-378.

Donovan GH, Rideout DB (2003) An integer programming model to optimize resource allocation for wildfire containment. Forest Science 49(2), 331-335.

Driscoll DA, Lindenmayer DB, Bennett AF, Bode M, Bradstock RA, Cary GJ, Clarke MF, Dexter N, Fensham R, Friend G, Gill M, James S, Kay G, Keith DA, MacGregor C, Possingham HP, Russel-Smith J, Salt D, Watson JEM, 
414 Williams D, York A (2010) Resolving conflicts in fire management using decision theory: asset-protection versus

Fried JS, Gilless JK, Spero J (2006) Analysing initial attack on wildland fires using stochastic simulation.

International Journal of Wildland Fire 15(1), 137-146.

Gill M (2005) Landscape fires as social disasters: An overview of the bushfire problem. Environmental Hazards 6(2), 65-80.

Gilless J, Fried J (2000) Generating beta random rate variables from probabilistic estimates of fireline production times. Annals of Operations Research 95(1), 205-215.

Gregory R, Failing L, Ohlson D, Mcdaniels T (2006) Some pitfalls of an overemphasis on science in environmental risk management decisions. Journal of Risk Research 9(7), 717-735.

Haight RG, Fried JS (2007) Deploying wildland fire suppression resources with a scenario-based standard response model. INFOR 45(1), 31-39.

Higgins A, Whitten S, Slijepcevic A, Fogarty L, Laredo L (2011) An optimisation modelling approach to seasonal resource allocation for planned burning. International Journal of Wildland Fire 20(2), 175-183.

Hillier F, Lieberman G (2005) 'Introduction to Operations Research.' ( McGraw-Hill: New York).

Hirsch K, Corey P, Martell D (1998) Using expert judgment to model initial attack fire crew effectiveness. Forest Science 44(4), 539-549.

Hirsch K, Podur J, Janser R, McAlpine R, Martell D (2004) Productivity of Ontario initial-attack fire crews: results of an expert-judgement elicitation study. Canadian Journal of Forest Research 34(3), 705-715.

Hoard M, Homer J, Manley W, Furbee P, Haque A, Helmkamp J (2005) Systems modeling in support of evidencebased disaster planning for rural areas. International journal of hygiene and environmental health 208(1-2), 117-125.

Hof J, Haight R (2007) Optimization of forest wildlife objectives. Handbook of Operations Research in Natural Resources, 405-418.

Hof J, Omi P (2003). Scheduling removals for fuels management. RMRS USDA Forest Service. Fire, fuel treatments, and ecological restoration: Conference proceedings RMRS-P 29, pp.367-378 (Fort Collins, CO).

Hof J, Omi P, Bevers M, Laven R (2000) A timing-oriented approach to spatial allocation of fire management effort. Forest Science 46(3), 442-451.

Hu X, Ntaimo L (2009) Integrated simulation and optimization for wildfire containment. ACM Transactions on Modeling and Computer Simulation (TOMACS) 19(4), 1-29. 
469

470

471

472

473

474

475

476

477

478

479

480

481

482

483

484

485

486

487

488

489

490

491

492

493

494

495

496

497

498

499

500

501

502

503

504

505

506

507

508

509

510

511

512

513

514

515

516

517

518

519

520

521

Iliadis L (2005) A decision support system applying an integrated fuzzy model for long-term forest fire risk estimation. Environmental Modelling \& Software 20(5), 613-621.

Iliadis L, Papastavrou A, Lefakis P (2002) A computer-system that classifies the prefectures of Greece in forest fire risk zones using fuzzy sets. Forest Policy and Economics 4(1), $43-54$.

Iliadis L, Papastavrou A, Lefakis P (2002b) A heuristic expert system for forest fire guidance in Greece. Journal of Environmental Management 65(3), 327-336.

Iliadis LS, Spartalis SI (2005) Fundamental fuzzy relation concepts of a DSS for the estimation of natural disasters' risk (The case of a trapezoidal membership function). Mathematical and Computer Modelling 42(7-8), 747-758.

Iliadis LS, Vangeloudh M, Spartalis S (2010) An intelligent system employing an enhanced fuzzy c-means clustering model: Application in the case of forest fires. Computers and Electronics in Agriculture 70(2), 276-284.

Kall P, Wallace S (1994) 'Stochastic Programming.' (Wiley: Chichester, UK).

Kaloudis S, Costopoulou C, Lorentzos N, Sideridis A, Karteris M (2008) Design of forest management planning DSS for wildfire risk reduction. Ecological Informatics 3(1), 122-133.

Kaloudis S, Tocatlidou A, Lorentzos N, Sideridis A, Karteris M (2005) Assessing wildfire destruction danger: a decision support system incorporating uncertainty. Ecological Modelling 181(1), 25-38.

Kennedy M, Ford E, Singleton P, Finney M, Agee J, USDA F (2008) Informed multi-objective decision-making in environmental management using Pareto optimality. Journal of Applied Ecology 45, 181-192.

Kirsch A, Rideout D (2005). Optimizing initial attack effectiveness by using performance measures. PNRS USDA Forest Service. System analysis in forest resources: Proceedings of the 2003 symposium. General Technical Report PNW-GTR-656, pp.183-188 (Portland, OR).

Konoshima M, Albers H, Montgomery C, Arthur J (2010) Optimal spatial patterns of fuel management and timber harvest with fire risk. Canadian Journal of Forest Research 40(1), 95-108.

Konoshima M, Montgomery C, Albers H, Arthur J (2008) Spatial-Endogenous Fire Risk and Efficient Fuel Management and Timber Harvest. Land Economics 84(3), 449.

Kumar T, Carty S, Parija G, Soni S (2010). Using Hybrid Goal Programming for Performing National Analysis of Wildland Fire Management in US. ' INFORMS Annual Meeting 2010', (Austin, Texas).

Lehmkuhl J, Kennedy M, Ford E, Singleton P, Gaines W, Lind R (2007) Seeing the forest for the fuel: integrating ecological values and fuels management. Forest Ecology and Management 246, 73-80.

Lundgren S (1999). The National Fire Management Analysis System (NFMAS) past 2000: A new horizon. PSRS USDA Forest Service. Fire economics, planning, and policy: Bottom lines. General Technical Report PSW-GTR-173 pp.71-78 (Albany, CA).

MacLellan JI, Martell DL (1996) Basing airtankers for forest fire control in Ontario. Operations Research 44(5), 677686.

Martell D (2007) Forest fire management. In 'Handbook of operations research in natural resources.' (Eds A Weintraub, C C Romero, T Bjorndal, R R Epstein and J Miranda) pp. 489-509. (Springer New York). 
522 Martell D (2011) The development and implementation of forest and wildland fire management decision support 523 systems: reflections on past practices and emerging needs and challenges. Mathematical and Computational Forestry 
577 Sheu J (2010) Dynamic relief-demand management for emergency logistics operations under large-scale disasters. 578 Transportation Research Part E 46(1), 1-17.

Sheu JB (2007) An emergency logistics distribution approach for quick response to urgent relief demand in disasters. Transportation Research Part E-Logistics and Transportation Review 43, 687-709.

Simpson N (2006) Modeling of residential structure fire response: Exploring the hyper-project. Journal of Operations Management 24(5), 530-541.

Smithson M (1991) The changing nature of ignorance. In 'New perspectives on uncertainty and risk.' (Eds J Handmer, B Dutton, B Guerin and M Smithson) pp. 5 - 38. (CRES/NDO: Canberra).

Snyder L (2006) Facility location under uncertainty: A review. IIE Transactions 38(7), 547-564.

Spring D, Kennedy J (2005) Existence value and optimal timber-wildlife management in a flammable multistand forest. Ecological Economics 55(3), 365-379.

Tan Q, Huang G, Wu C, Cai Y, Yan X (2009) Development of an inexact fuzzy robust programming model for integrated evacuation management under uncertainty. Journal of Urban Planning and Development 135, 39-49.

Teague B, Mc Leod R, Pascoe S (2010). 2009 Victorian Bushfires Royal Commission - Final Report. Parliament of Victoria. (Melbourne, Australia).

Tsataltzinos T, Iliadis L, Stefanos S (2009) Sensitivity analysis of forest fire risk factors and development of a corresponding fuzzy inference system: the case of Greece. In 'Engineering applications of neural networks.' (Eds D Palmer-Brown, C Draganova, E Pimenidis and H Mouratidis) pp. 313-324. (Springer-Verlag: Berlin Heidelberg).

Venn TJ, Calkin DE (2011) Accommodating non-market values in evaluation of wildfire management in the United States: challenges and opportunities. International Journal of Wildland Fire 20(3), 327-339.

Verderame PM, Elia JA, Li J, Floudas CA (2010) Planning and scheduling under uncertainty: a review across multiple sectors. Industrial \& Engineering Chemistry Research 49(9), 3993-4017.

Vladimirou H, Zenios S (1997) Stochastic programming and robust optimization. In 'Advances in sensitivity analysis and parametric programming.' (Eds T Gal and H Greenberg) pp. 12.11-12.53. (Kluwer Norwell MA).

Wei Y, Rideout D, Kirsch A (2008) An optimization model for locating fuel treatments across a landscape to reduce expected fire losses. Canadian Journal of Forest Research 38(4), 868-877.

Westerling AL, Hidalgo HG, Cayan DR, Swetnam TW (2006) Warming and earlier spring increase western US forest wildfire activity. Science 313(5789), 940.

Wiitala M (1999). A dynamic programming approach to determining optimal forest wildfire initial attack responses. PSRS USDA Forest Service. Fire economics, planning, and policy: Bottom lines. General Technical Report PSWGTR-173 pp.115-123 (Albany, CA).

Williams HP (1990) 'Model building in mathematical programming.' (John Wiley \& Sons: Chichetser, UK).

Winston WL (1994) 'Operations research: applications and algorithms.' (Duxbury Press: Belmont, CA).

Wolsey LA (1998) 'Integer programming.' (Wiley-Interscience: New York, NY).

Wotton B, Martell D, Logan K (2003) Climate change and people-caused forest fire occurrence in Ontario. Climatic Change 60(3), 275-295. 
632 Yao T, Mandala SR, Chung BD (2009) Evacuation Transportation Planning Under Uncertainty: A Robust 633 Optimization Approach. Networks and Spatial Economics 9(2), 171-189. 